\title{
Circulatory assistance for the failing heart
}

\author{
Leon Resnekov \\ From the Section of Cardiology, Department of Medicine, University of Chicago, Chicago, Illinois, U.S.A.
}

Although coronary care units have been successful in reducing the in-hospital mortality after acute myocardial infarction, this is largely a result of preventing and treating dysrhythmias. The failing myocardium remains a therapeutic challenge and current medical therapy disappointing. Methods of providing the heart with mechanical support are described and indications and contraindications to their use are detailed. The results of clinical trials are reported, including the use of bypass pumps and especially the intra-aortic balloon. A recent advance has been the availability of noninvasive support techniques, and results using external synchronous compression are detailed. All methods of circulatory support require careful documentation of claims of their effectiveness. Emphasis should be placed on demonstrating improved myocardial perfusion, preservation of myocardial cells, and reduction in size of the infarct since mortality rates continue to be unacceptably high despite initial haemodynamic improvement even when circulatory support is combined with emergency selective coronary arteriography and direct coronary arterial surgery.

Coronary care units (Brown et al., 1963; Day, 1963) have had a profound effect on the in-hospital mortality of acute myocardial infarction (Hofvendahl, 197I). The number of patients suffering coronary heart disease, however, indicates that greater emphasis is needed on preventing its occurrence rather than treating its acute complications if a significant number of the population is to be saved. Nevertheless, mortality figures from coronary care units now indicate fatality in 8 to 9 per cent as reported by Resnekov (1972) based on an analysis of 366 consecutive admissions of patients with proven acute myocardial infarction. Further breakdown of these results, however, shows that the welcome decline in mortality has followed more efficient prevention, recognition, and management of acute dysrhythmias; the failing myocardium in association with acute myocardial infarction remains a therapeutic challenge. When cardiac failure is severe, cardiac output less than $2.01 . / \mathrm{min}$ and the left ventricular filling pressure exceeds $15 \mathrm{mmHg}$, a mortality of 90 per cent or more can be expected - a figure based on 151 patients studied in the early hours following acute myocardial infarction (MIRU Studies, 1972).

The drug management of severe cardiac failure associated with myocardial infarction can be summarized as follows. When the ventricular filling Received 30 July 1973.

1 Part of the work described is supported by USPHS Contract (Myocardial Infarction Research Unit). pressure is normal or low, initial treatment should be intravenous fluid; an inadequate ventricular filling pressure persisting despite increasing the circulating blood volume should then be managed with noradrenaline or dopamine. When the cardiac output is much reduced, left ventricular filling pressure high, tissue perfusion inadequate, and the systemic vascular resistance increased, drugs to be tried should include isoprenaline, digitalis, and glucagon; more recently alpha-adrenergic blockade has been advocated for these patients (Majid, Sharma, and Taylor, 197I). Finally, when vagal tone is inappropriate, intravenous atropine may have dramatic effects. Even when drugs are given, controlled by careful haemodynamic measurements, the results are frequently disappointing - especially in the group of patients with pronounced reduction of cardiac output and high ventricular filling pressures.

Unlike the dysrhythmia problem when a lifethreatening situation may occur with a relatively small area of myocardial necrosis, pathology studies (Caulfield, Dunkman, and Leinbach, 1972) have shown that cardiogenic shock and death occur when at least 40 to 50 per cent of the left ventricular myocardium has been damaged. The clinical syndrome is commonest after a second or third episode of infarction and when important occlusive disease of the left anterior descending and circumflex arteries is present. Isolated single lesions are less commonly associated with cardiogenic shock, particularly obstruction of the right coronary artery. 
The prognosis, therefore, will depend not only on the functional integrity of the myocardium immediately after the infarct but also on the degree of recovery that will occur after the most recent acute ischaemic episode. The failure of drug therapy to affect significantly the mortality of cardiogenic shock continues to stimulate a large amount of research into alternative approaches of which the most favoured at the present time is temporary circulatory assistance with or without direct coronary arterial surgery.

Shortly after Gibbon (1952) showed that total circulatory support was feasible for open heart surgery, Stuckey et al. (1958) reported using venoarterial bypass in 3 patients in cardiogenic shock after myocardial infarction, one of whom was discharged home from hospital. Harken (1958) proposed arterial counterpulsation to produce diastolic augmentation, and a counterpulsator pump with a stroke of $70 \mathrm{ml}$ was designed by Clauss et al. (1961). In 1962, Moulopoulos, Topaz, and Kolff described the intra-aortic phase-shift balloon pump. Other approaches which have been suggested include left heart bypass by transseptal cannulation of the left atrium from the internal jugular vein (Dennis et al., I962) since venoarterial bypass was shown to worsen left ventricular failure in the experimental animal (Salisbury et al., 1960). More recently an 'inseries' auxiliary ventricle has been described by Kantrowitz et al. (1966), an implantable bypass pump for left ventricular assistance by DeBakey, Liotta, and Hall (1966), and closed left ventricular bypass by Zwart et al. (1969).

All these approaches, however, require surgical intervention, frequently complex and often time consuming. In contrast, the ideal, if feasible, might be to provide the patient with circulatory support which is noninvasive, easy to use, and which does not commit him to major surgery.

Two such approaches have been proposed. (i) Synchronous counterpulsation by external compression (Dennis et al., 1963; Osborn et al., 1964; Birtwell et al., 1965) and (ii) body acceleration synchronous with the heart beat (Arntzenius, Koops, and Hugenholtz, 1969).

Whether an invasive or noninvasive method of circulatory support is used, the objectives of the intervention should be clearly defined. It is likely that all devices should be capable of providing support for hours or days as needed until myocardial function is adequate. This does not, of course, preclude using drug therapy at the same time or undertaking direct coronary arterial surgery during the acute phase of the illness if required. Circulatory support should reduce external myocardial work, restore the balance beyween myocardial oxygen supply and demand, improve tissue perfusion, and, if possible, reduce the extent of myocardial damage by maintaining the viability of injured myocardial cells. The type of patient who requires mechanical support is usually in severe left ventricular failure after myocardial infarction with a systolic blood pressure of $90 \mathrm{mmHg}$ or less or some 30 to $40 \mathrm{mmHg}$ below the previously known blood pressure, the cardiac output is often $\mathbf{2 \cdot 2} \mathrm{l} . / \mathrm{min}$ or less, the pulmonary systemic arteriovenous difference is usually wider than $60 \mathrm{ml} / \mathrm{l}$; severe peripheral vasoconstriction may occur and mental clouding be associated. The incidence of this full-blown syndrome of cardiogenic shock varies from 5 per cent (Pantridge, 1970) to Io per cent (Swan et al., 1970; Scheidt, Ascheim, and Killip, 1970) depending on the population under review and possibly also on the speed and success of stabilizing dysrhythmias after the acute episode (Adgey et al., 1971).

Most investigators stress the importance of providing the patient with adequate treatment when severe ventricular failure is known to be present before the full-blown syndrome associated with severe vasoconstriction has developed. As yet, there are no firm prognostic indices to indicate with certainty that cardiogenic shock will follow myocardial infarction; but as already indicated, the seriousness of a very reduced cardiac output and a high ventricular filling pressure, particularly after a second or third myocardial infarction, cannot be overemphasized.

The contraindications to mechanical assistance, perhaps as important to bear in mind as the indications, can be stated as follows.

(i) Terminal or untreatable associated disease.

(ii) Brain damage deemed irreversible.

(iii) Aortic valvar regurgitation for any method requiring backward displacement of arterial blood towards the heart.

(iv) Arterial wall disease, including severe atherosclerosis and dissecting aneurysm for any method depending on arterial surgery.

(v) Ventricular fibrillation or asystole for any method requiring synchronization of mechanical assistance with electrical activity of the heart.

Of the many forms of circulatory assistance proposed or designed, the following are undergoing clinical trials at the present time (Table).

\section{A. Invasive methods}

\section{(i) Bypass pumps}

In cardiopulmonary bypass blood is led from a major vessel or chamber on the venous side, oxygenated either using a disc or bubble method or 
TABLE Circulatory assistance methods undergoing clinical trial

\author{
A: Invasive \\ (i) Bypass pumps \\ Venoarterial \\ Left atrial bypass \\ Left ventricular bypass \\ (ii) Counterpulsation diastolic augmentation \\ Intra-aortic balloon \\ Arterioarterial \\ (iii) Cardiac compression \\ Anstadt cup
}

B: Noninvasive

(i) External synchronous compression

(ii) Body acceleration synchronous with heart beat

more recently a membrane oxygenator (Bramson et al., 1969), and returned to the arterial side either in a pulsatile or nonpulsatile mode. While ideally the power source should be as small and as efficient as possible, at the present time these are usually large free-standing devices. Experience with venoarterial circulatory assistance after myocardial infarction has been limited, and published results have not been encouraging (Stuckey et al., 1958; Joseph and Maloney, 1965; Kennedy and Bricker, 1971), possibly due to the fact that additional myocardial work is required since arterial pressure is raised both during systole and diastole. In addition there are formidable problems when perfusion is prolonged for more than 4 hours as trauma to the blood produces haemolysis and destroys coagulation factors.

Closed-chest left ventricular bypass (Zwart et al., 1969) can be achieved by withdrawing blood from the left ventricle via retrograde cannulation of the subclavian artery, the arterial blood being reinfused into the aorta during diastole thereby also producing diastolic augmentation. Clinical trial of the method, however, has been very limited (Zwart et al., 1972). Similarly, left atrial bypass by transseptal cannulation of the left atrium from the internal jugular vein (Dennis et al., 1962), while theoretically attractive, has also had very little clinical trial.

Other bypass methods proposed have included an in-series auxiliary left ventricle which was implanted by Kantrowitz, Krakauer, and Sherman (1968) in one patient. Though experimental studies continue to be encouraging (Bernhard et al., 1970), it will undoubtedly be several years before a total implantable bypass pump is available for human use (Bernhard et al., 1969).

\section{(ii) Counterpulsation and diastolic augmenta- tion}

Much more clinical experience is available using counterpulsation and diastolic augmentation following the original experimental work of Kantrowitz and McKinnon (1958). An ingenious development has been the intra-aortic phase-shift synchronous balloon (Moulopoulos et al., 1962). In this method a catheter to which a $30 \mathrm{ml}$ volume balloon is attached is introduced into the aorta from the femoral artery and positioned with its tip just distal to the left subclavian artery. The balloon size is important; it should not occlude the aorta, but its diameter should not be less than 85 per cent of the arterial lumen. Inflation is obtained by pumping carbon dioxide or helium into the balloon phased with the $\mathbf{R}$ wave of the electrocardiogram to occur during diastole; fail-safe circuits prevent incorrect inflation during systole or after a premature beat. These electronic circuits are now reliable, and the unit is capable of accurately following sinus rhythm to a rate of 170 to $180 / \mathrm{min}$. The haemodynamic effects of properly phased intra-aortic diastolic balloon augmentation are as follows (Buckley et al., 1970).

(a) Peak systolic left ventricular pressure is decreased.

(b) End-diastolic pressure of the left ventricle is reduced.

(c) Mean aortic diastolic pressure is increased.

(d) Cardiac output is increased.

(e) Coronary arterial diastolic filling is enhanced.

The net result is a reduction in both left ventricular pre-load and after-load. Myocardial oxygen consumption is, therefore, diminished and an improvement is achieved in overall myocardial perfusion and performance.

Animal experimental work has shown that the method not only decreases infarct size (Sugg, Webb, and Ecker, 1969) but, equally important, reduces the current of injury at the margins of the lesion (Maroko et al., 1970). The combined beneficial effects might, therefore, be to preserve viability of compromised myocardial cells (Caulfield et al., 1972).

The method has now been used in more than roo patients (Sanders et al., 1972; Scheidt et al., 1973), and improvement in the clinical and haemodynamic status was achieved in 75 per cent. Though initial improvement is gratifying, the subsequent course of patients remains a great problem, for the ultimate mortality still exceeds 80 per cent. The method is complex, a skilful team has to be available at all times, and initial surgery is required. Those who cannot be weaned off the apparatus within 24 to 48 
hours are assessed by selective coronary arteriography and left ventricular function studies to determine whether coronary revascularization surgery is feasible (Buckley et al., 1971 ; Sanders et al., 1972; Mundth et al., 1972). Even so, overall results remain less than ideal, and the number of patients who leave hospital alive continues to be disappointingly small (Corday, Meerbaum, and Tzu-Wang Lang, 1972). In addition, complications to intraaortic balloon pumping include death due to rupture of the balloon, peripheral and renal embolization, myocardial rupture, and trauma to the femoral artery or aorta with varying grades of arterial insufficiency requiring reparative surgery.

Arterioarterial pumping Watkins and Callaghan (1965) were able to support the circulation in man by withdrawing blood close to the aortic valve during systole, reinfusing it at the same site in early diastole; encouraging preliminary clinical results were also reported by Rosensweig, Chatterjee, and Merino (1970). Though the method will reduce left ventricular afterload and preload and provide diastolic augmentation, there remain formidable limitations to its use including damage to blood components and intravascular clotting.

\section{(iii) Cardiac compression}

Direct compression of the heart has been used particularly when ventricular fibrillation is present, and the Anstadt cup (Anstadt, Schiff, and Baue, 1966) has been evaluated most extensively (Skinner, I97I). Though capable of maintaining the circulation, it does require thoracotomy and can only be used for several hours thereby limiting its use in practice.

\section{B. Noninvasive methods}

\section{(i) External synchronous compression}

Because of the inherent difficulties of all invasive approaches, Dennis and his team (1963) designed a noninvasive form of diastolic augmentation which was subsequently tried clinically by Soroff et al. (1969), Resnekov (1972), Michael et al. (1972), and Al-Sadir et al. (I973). In this method the legs of the patient are enclosed in a rigid plastic box and surrounded by a bladder which is inflated and deflated in diastole and systole, respectively, by a rapidly acting mechanical pump and hydraulic pressure. As with the intra-aortic balloon, fail-safe electronic ciruits prevent misfiring during systole, and the unit will follow a heart rate up to $160 / \mathrm{min}$. Squeezing the legs during diastole forces the column of arterial blood back towards the heart thus providing diastolic augmentation and better coronary arterial filling. Though some reduction in left ventricular afterload is produced and also reduction in end-diastolic left ventricular pressure (preload) occurs, in general the method is less efficient in reducing these important parameters than is the intraaortic ballon. Nevertheless, in our own unit we have been able to achieve augmentation of the cardiac output when depressed by 25 per cent, and both peak and mean aortic diastolic pressure augmentation are easily obtained (Resnekov, 1972; AlSadir et al., I973). It is possible that when the negative phase of this noninvasive apparatus is combined with the positive pressure that left ventricular preload will be reduced more efficiently, and preliminary studies in our unit suggest that this is so.

Very few untoward side-effects have been reported in man, nor does there appear to be any increased risk of precipitating pulmonary emboli or unduly raising the venous pressure on the right side of the heart, but certain patients do complain of local discomfort in the legs after several hours. We are now investigating its use in reducing the area of myocardial damage after acute myocardial infarction using a combined mobile pho-gamma camera and data acquisition system and the intravenous injection of the short half-life nuclide ${ }^{13} \mathrm{NH}_{3}$ to obtain a myocardial image at the bedside (Schwartz et al., 1972). Apart from its use in the management of cardiogenic shock and severe left ventricular failure, the method may also be beneficial in the management of intractable angina pectoris, possibly by enhancing the collateral circulation (Banas et al., 1972). A disadvantage of the machine is the difficulty of maintaining circulatory support in patients who require selective coronary arteriography unless special radiological equipment is used which obviates the need for moving the patient into lateral and oblique positions during filming.

A modification of the original method permitting sequenced external pressure with sleeves on all four limbs has been described by Cohen, Mullins, and Mitchell (1970), but there do not as yet appear to be any clinical trials reporting its use.

\section{(ii) Body acceleration synchronous with heart beat}

The second major method of providing noninvasive circulatory assistance is body acceleration synchronous with the heart beat (Arntzenius et al., 1969). A specially designed table capable of moving very rapidly in the horizontal position at forces exceeding gravity is used. Blood in the aorta is pushed away from the thorax towards the legs during systole thus reducing left ventricular afterload and during diastole pressure is augmented by the elastic recoil of the column of arterial blood back towards the 
heart. No published clinical trials are as yet available.

It is apparent that despite the enormous amount of effort of many groups working in circulatory assistance there is as yet no proof that either invasive or noninvasive methods significantly reduce inhospital mortality after myocardial infarction. They will, however, permit very ill patients to undergo selective coronary arteriography and other studies to determine the need for and feasibility of direct coronary arterial surgery or infarctectomy which otherwise could not be done. Patients should be considered for supportive treatment early in the course of their complicated myocardial infarction and wherever possible before the full-blown syndrome of cardiogenic shock has been allowed to develop. All methods currently being used require that their claims for effectiveness be carefully investigated in clinical use with particular emphasis on the demonstration of improved myocardial perfusion, preservation of the viability of myocardial cells, and reduction in the size of the infarct. With the limited number of patients available in any one centre, it is likely that studies of this type will provide more meaningful data when units combine to investigate the problem using a joint protocol rigorously controlled.

\section{References}

Adgey, A. A. J., Allen, J. D., Geddes, J. S., James, R. G. G., Webb, S. W., Zaidi, S. A., and Pantridge, J. F. (1971). Acute phase of myocardial infarction. Lancet, 2, $50 \mathrm{r}$.

Al-Sadir, J., Zimmet, L., Brooks, H., King, S., and Resnekov, L. (1973). Hemodynamic evaluation of external counterpulsation in acute myocardial infarction. Clinical Research, 21, 396.

Anstadt, G. L., Schiff, P., and Baue, A. E. (1966). Prolonged circulatory support by direct mechanical ventricular assistance. Transactions. American Society for Artificial Internal Organs, 12, 72.

Arntzenius, G. L., Koops, J., and Hugenholtz, P. G. (1969). Cardiovascular response in piglets to body acceleration given synchronously with the heart beat (BASH) (abstract). Circulation, 40, Suppl. III, 38.

Banas, J. S., Brilla, A., Soroff, H. S., and Levine, H. J. (1972). Evaluation of external counterpulsation for the treatment of severe angina pectoris (abstract). Circulation, 46, Suppl. II, II-74.

Bernhard, W. F., LaFarge, C. G., Husain, M., Yamamura, N., and Robinson, T. C. (1970). Physiologic observations during partial and total left heart bypass. Fournal of Thoracic and Cardiovascular Surgery, 60, 807.

Bernhard, W. F., LaFarge, C. G., Kritrilakis, S., and Robinson, T. (1969). Left ventricular-aortic assist device. In Proceedings of the Artificial Heart Program Conference, p. 559. Government Printing Office, Washington, D.C.

Birtwell, W., Giron, F., Soroff, H., Ruiz, V., Collins, J., and Deterling, R. (I965). Support of the systemic circulation and left ventricular assist by synchronous pulsation of extramural pressure. Transactions. American Society for Artificial Internal Organs, II, 43.
Bramson, M. L., Hill, J. D., Osborne, J. J., and Gerbode, F. (1969). Partial veno-arterial perfusion with membrane oxygenation and diastolic agumentation. Transactions. American Society for Artificial Internal Organs, 15, 412.

Brown, K. W. G., MacMillan, R. L., Forbath, N., Mel'grano, F., and Scott, J. W. (1963). Coronary unit. An intensivecare centre for acute myocardial infarction. Lancet, 2, 349.

Buckley, M. J., Leinbach, R. C., Kastor, J. A., Laird, J. D., Kantrowitz, A. R., Madras, P. N., Sanders, C. A., and Austen, W. G. (1970). Hemodynamic evaluation of intraaortic balloon pumping in man. Circulation, 41, Suppl. II, II-I30.

Buckley, M. J., Mundth, E. D., Daggett, W. M., DeSanctis, R. W., Sanders, C. A., and Austen, W. G. (1971). Surgical therapy for early complications of myocardial infarction. Surgery, 70, 814 .

Caulfield, J. B., Dunkman, W. B., and Leinbach, R. C. (1972). Cardiogenic shock: myocardial morphology with and without artificial left ventricular counterpulsation. Archives of Pathology, 93, 532.

Clauss, R. H., Birtwell, W. C., Albertal, G., Lunzer, S., Taylor, W. J., Fosberg, A. M., and Harken, D. E. (I96I). Assisted circulation: I. The arterial counterpulsator. Fournal of Thoracic and Cardiovascular Surgery, 4I, 447.

Cohen, L. S., Mullins, C. B., and Mitchell, J. H. (I970). Sequenced external counterpulsation and intra-aortic balloon pumping in cardiogenic shock (abstract). Circulation, 42, Suppl. III, III-8I.

Corday, E., Meerbaum, S., and Tzu-Wang Lang (1972). Treatment of cardiogenic shock with mechanical circulatory assist - fact or fiction? American fournal of Cardio$\log y, 30,575$.

Day, H. W. (1963). An intensive coronary care area. Diseases of the Chest, 44, 423.

DeBakey, M. E., Liotta, D., and Hall, C. W. (1966). Left heart bypass using an implantable blood pump. In Mechanical Devices to Assist the Failing Heart, p. 223. National Academy of Sciences, National Research Council, Washington, D.C.

Dennis, C., Carlens, E., Senning, A., Hall, D. P., Moreno, J. R., Cappelletti, R. R., and Weselowski, S. A. (I962). Clinical use of a cannula for left heart bypass without thoracotomy. Annals of Surgery, 156, 623.

Dennis, C., Moreno, J. R., Hall, D. P., Gross, C., Ross, S. M., Wesolowski, S. A., and Senning, A. (I963). Studies on external counterpulsation as a potential measure for acute left heart failure. Transactions. American Society for Artificial Internal Organs, 9, 186.

Gibbon, J. H. (1952). The present status of the mechanical heart and lungs. Medical Record and Annals, 46, 872.

Harken, D. E. (1958). International College of Cardiology Meeting, Brussels.

Hofvendahl, S. (1971). Influence of treatment in a coronary care unit on prognosis in acute myocardial infarction. Acat Medica Scandinavica, Suppl. 519.

Joseph, W. L., and Maloney, J. V., Jr. (I965). Extracorporeal circulation as an adjunct to resuscitation of the heart. Fournal of the American Medical Association, 193, 683.

Kantrowitz, A., Akutsu, T., Chaptal, P. A., Krakauer, J., Kantrowitz, A. R., and Jones, R. T. (1966). A clinical experience with an implanted mechanical auxiliary ventricle. Fournal of the American Medical Association, 197, 525.

Kantrowitz, A., Krakauer, J., and Sherman, J. L., Jr. (1968). A permanent mechanical auxiliary ventricle: experimental and clinical experience. Fournal of Cardiovascular Surgery, 9, 1 .

Kantrowitz, A., and McKinnon, W. M. P. (1958). Experimental use of the diaphragm as an auxiliary myocardium Surgical Forum, 9, 266. 
Kennedy, J. H., and Bricker, D. L. (197I). Criteria for selection of patients for mechanical circulatory support. American fournal of Cardiology, 27, 33.

Majid, P. A., Sharma, B., and Taylor, S. H. (197I). Phentolamine for vasodilator treatment of severe heart-failure. Lancet, 2, 719.

Maroko, P. R., Watanabe, T., Covell, J. W., Braunwald, E., Bernstein, E. F., and Ross, J. (1970). The effect of positive inotropic agents and counterpulsation on myocardial ischemic injury following experimental coronary occlusion (abstract). Circulation, 42, Suppl. III, III-8I.

Michael, T. D., Bassan, M., Chatterjee, K., Forrester, J., Parmley, W. W., and Swan, H. J. C. (1972). Hemodynamic and metabolic effects of non-invasive circulatory assist (Cardiassist) (abstract). Circulation, 46, Supp. II, III92.

Moulopoulos, S. D., Topaz, S., and Kolff, W. J. (1962). Diastolic balloon pumping (with carbon dioxide) in the aorta: a mechanical assistance to the failing circulation. American Heart fournal, 63, 669.

Mundth, E. D., Buckley, M. J., Daggett, W. M., Sanders, C. A., and Austen, W. G. (1972). Surgery for complications of acute myocardial infarction. Circulation, 45, 1279.

Myocardial Infarction Research Unit Studies (1972). Co-operative investigators.

Osborn, J. J., Russi, M., Salil, A., Bramson, M. L., and Gerbode, F. (1964). Circulatory assistance by external pulsed pressures. American fournal of Medical Electronics, 3,87 .

Pantridge, J. F. (1970). Mobile coronary care. Chest, 58, 229.

Resnekov, L. (1972). University of Chicago Myocardial Infarction Research Unit. Comprehensive clinical and laboratory research. USPHS Report PH-43-68-1334-A. 73.

Rosensweig, J., Chatterjee, S., and Merino, F. (1970). Treatment of acute myocardial infarction by counterpulsation: experimental rationale and clinical experience. fournal of Thoracic and Cardiovascular Surgery, 59, 243.

Salisbury, P. F., Cross, C. E., Rieben, P. A., and Lewin, R. J. (1960). Comparison of two forms of mechanical assistance in experimental heart failure. Circulation Research, 8, 431.

Sanders, C. A., Buckley, M. J., Leinbach, R. C., Mundth, E. D., and Austen, W. G. (1972). Mechanical circulatory assistance: current status and experience with combining circulatory assistance, emergency coronary angiography, and acute myocardial revascularization. Circulation, 45, I292.
Scheidt, S., Ascheim, R., and Killip, T., III (1970). Shock after acute myocardial infarction: a clinical and hemodynamic profile. American fournal of Cardiology, 26, 556.

Scheidt, S., Wilner, G., Mueller, H., Summers, D., Lesch, M., Wolff, G. Krakauer, J., Rubenfire, M., Fleming, P., Noon, G., Oldham, N., Killip, T., and Kantrowitz, A. (1973). Intra-aortic balloon counterpulsation in cardiogenic shock. New England fournal of Medicine, 288, 979.

Schwartz, J., Harper, P., Brooks, H., Al-Sadir, J., Resnekov, L., and Lambares, N. (1972). Detection of myocardial infarction by myocardial imaging (abstract). Circulation, 46, Suppl. II, II-I5.

Skinner, D. B. (197I). Experimental and clinical evaluations of mechanical ventricular assistance. American fournal of Cardiology, 27, 146.

Soroff, H. S., Giron, F., Ruiz, U., Birtwell, W. C., Hirsch, L. J., and Deterling, R. A. (1969). Physiologic support of heart action. New England fournal of Medicine, 280, 693.

Stuckey, J. H., Newman, M. M., Dennis, C., Berg, E. H., Goodman, S. E., Fries, C. C., Karlson, K. E., Blumenfield, M., Weitzner, S. W., Binder, L. A., and Winston, A. (1958). Use of heart-lung machine in selected cases of acute myocardial infarction. Surgical Forum, 8, 342.

Sugg, W. L., Webb, W. R., and Ecker, R. R. (1969). Reduction of extent of myocardial infarction by counterpulsation. Annals of Thoracic Surgery, 7, 310.

Swan, H. J. C., Forrester, J. S., Danzig, R., and Allen, H. N. (1970). Power failure in acute myocardial infarction. Progress in Cardiovascular Diseases, 12, 568.

Watkins, D. H., and Callaghan, P. B. (1965). Postsystolic myocardial augmentation. Archives of Surgery, 90, 544.

Zwart, H. H. J., Kralios, A., Collan, R., and Kolff, W. J. (1969). Transarterial closed-chest left ventricular (TaCLV) bypass. Transactions. American Society for Artificial Internal Organs, 15, 386.

Zwart, H. H. J., Kralios, A. C., Eastwood, N., and Kolff, W. J. (1972). Effects of partial and complete unloading of the failing left ventricle by transarterial left heart bypass. fournal of Thoracic and Cardiovascular Surgery, 63, 865 .

Requests for reprints to Dr. Leon Resnekov, Department of Medicine, Box 423, University of Chicago, 950 East 59th Street, Chicago, Illinois 60637 , U.S.A. 